\title{
Gambling expenditure by game type among weekly gamblers in Finland
}

\author{
Anne H. Salonen ${ }^{1,2^{*}}$, Jukka Kontto ${ }^{3}$, Riku Perhoniemi ${ }^{1}$, Hannu Alho ${ }^{1,4}$ and Sari Castrén ${ }^{1,5}$
}

\begin{abstract}
Background: Excessive expenditure and financial harms are core features of problem gambling. There are various forms of gambling and their nature varies. The aim was to measure gambling expenditure by game type while controlling for demographics and other gambling participation factors. A further aim was to find out how each game type was associated with gambling expenditure when the number of game types played is adjusted for.

Methods: Using data from the 2015 Finnish Gambling survey on adult gamblers ( $n=3555)$, multiple log-linear regression was used to examine the effects of demographics, gambling participation, and engaging in different game types on weekly gambling expenditure (WGE) and relative gambling expenditure (RGE).

Results: Male gender, lower education level, higher gambling frequency and higher number of game types increased both WGE and RGE, while younger age decreased WGE but increased RGE. Furthermore, seven specific game types increased both WGE and RGE. Weekly horse race betting and non-monopoly gambling had the strongest increasing effect on expenditure. Betting games and online poker were associated with higher expenditure even when they were played less often than weekly. Among weekly gamblers the highest mean WGE was recorded for those who played non-monopoly games (146.84 €/week), online poker (59.61 €/week), scratch games (51.77 €/week) and horse race betting (48.67 €/week). Those who played only $1-2$ game types a week had the highest mean WGE and RGE on horse race betting and other betting games.

Conclusions: It seems that overall gambling frequency is the strongest indicator of high gambling expenditure. Our results showed that different game types had different effect sizes on gambling expenditure. Weekly gambling on horse races and non-monopoly games had the greatest increasing effect on expenditure. However, different game types also varied based on their popularity. The extent of potential harms caused by high expenditure therefore also varies on the population level. Based on our results, future prevention and harm minimization efforts should be tailored to different game types for greater effectiveness.
\end{abstract}

Keywords: Cross-sectional, Game type, Gambling expenditure, Net income, Population study, Relative gambling expenditure

\section{Background}

Early research into the adverse consequences of gambling was focused on the presence of pathological or problem gambling, but recently it has become commonplace to take a broader view on gambling harm $[1,2]$. Some game types, for example, slot machine gambling, casino games, poker, betting games, bingo and/or scratch games have been associated with gambling-related problems (e.g. [3-8]). On the

\footnotetext{
* Correspondence: anne.salonen@thl.fi

${ }^{1}$ Alcohol, Drugs and Addictions Unit, National Institute for Health and Welfare, P.O. Box 30, FI-00271 Helsinki, Finland

${ }^{2}$ Faculty of Health Sciences, University of Eastern Finland, Kuopio, Finland Full list of author information is available at the end of the article
}

other hand, it has been suggested, that some game types may be more like indicators of unhealthy gambling involvement, rather than critical factors associated with gambling-related problems [9, 10]. Gambling expenditure, one of the indicators of unhealthy gambling involvement, shows the strongest association with gambling-related harm as many of the negative impacts of excessive gambling are due to financial problems $[1,2,11-14]$. Despite this association, gambling problem or even gambling-related financial harm are not synonymous with excessive expenditure $[15,16]$. For harm prevention and minimization purposes it is essential that we

(c) The Author(s). 2018 Open Access This article is distributed under the terms of the Creative Commons Attribution 4.0 International License (http://creativecommons.org/licenses/by/4.0/), which permits unrestricted use, distribution, and 
build our understanding of different game types and associated harms. There is as yet very little research on gambling expenditure by game type.

Finland has one of the highest per capita gambling expenditure rates in Europe [17]. For research purposes gambling expenditure is usually assessed by questions concerning wins and losses, or most typically by direct questions on spending; the latter is the most common way [18]. However, it has been suggested that in order to gain a clearer picture of gambling-related harm, gambling expenditure should be examined in relation to the gambler's net income [2]. We use the dual measures of weekly gambling expenditure and gambling expenditure in relation to the gambler's net income.

Gambling expenditure is higher among men than women [19-23]. Furthermore, low education and unemployment are associated with higher gambling expenditure [20, 24, 25]. Overall, people with high monthly gambling expenditure relative to net income, and men in particular, are more likely to be socio-economically vulnerable individuals [26].

Gambling frequency is typically assessed by asking people how many times they have engaged in gambling within a certain period of time, or by asking their average frequency of participation within a certain time frame [18]. A high frequency of gambling, participation in multiple game types and high gambling severity are associated with high total expenditure [27-29]. Although high gambling frequency is associated with gambling harms, only some frequent gamblers experience harm [30]. On the other hand, even occasional gamblers may experience harm [11, 13, 31].

There are various forms of gambling and their nature varies [32]. A simple classification distinguishes between lottery-style and wagering-style games. Another classification is based on game provider [18]. Finland is one of the countries where games are provided by a government regulated monopoly, although non-monopoly games are available online. Game types can also be classified based on means of access, such as direct face-to-face gambling or remote access [18]. Another access-based classification distinguishes between online and land-based games [32]. Furthermore, game types are classified based on whether their outcome is determined by chance, skill or a combination of chance and skill [33]. Games such as slot machines, lotteries, scratch cards, bingos, roulettes and dice games are fundamentally chance-based games, whereas poker and blackjack, for instance, also include elements of skill [34]. Another way to categorize game types is to look at their structural characteristics, which are event frequency, event duration, bet frequency and pay out interval [5]. In population studies, a common way of inquiring about participation in different gambling types is to use a list of available game types [18].
There is gender differences in game type preferences: men tend to favour skill-based games, whereas women prefer games of chance [35]. Game type preferences were highly gendered in Sweden, although men in Sweden have decreased their participation in games of strategy and increased participation in games of chance in public spaces [36]. In any assessment of gambling participation, it is therefore important to consider both the number of different game types played and the frequency of gambling $[7,9,10,46]$. Playing multiple game types is associated with online gambling, and among females in particular online gambling may be related to higher gambling expenditure and at-risk and problem gambling [37].

In 2015, 23\% of Finns gambled only one game type, predominantly weekly lottery games [20]. It is beneficial to take a broader view on gambling participation and also consider overall gambling frequency, gambling mode and number of game types gambled. Furthermore, an examination of different game types played by active gamblers and more occasional gamblers is a novel way of studying patterns of gambling expenditure and relative expenditure concurrently.

\section{Methods}

\section{Aim, design and setting}

This cross-sectional study aims to measure gambling expenditure by game type while controlling for demographics and other gambling participation factors, such as gambling frequency, number of game types played and gambling mode. We used two measures of gambling expenditure: weekly gambling expenditure and gambling expenditure in relation to net income. A further aim was to find out how each game type is associated with gambling expenditure when the number of game types played is adjusted for.

Until December 2016, Finland had a three-way monopoly system (Veikkaus, Finland's Slot Machine Association [FSMA] and Fintoto) in which each game provider had the right to offer gambling services [38]. In 2017, these service operators were merged into a single company.

\section{Data collection}

The data were drawn from the Finnish Gambling 2015 survey [20]. A random sample of 7400 persons aged 15-74 whose mother tongue was Finnish or Swedish and who resided in mainland Finland were approached by Statistics Finland. In total 4515 computer-assisted telephone interviews lasting on average $18 \mathrm{~min}$ were completed. The study was described to the potential participants as a survey about 'gambling and opinions about gambling'. The response rate was $62 \%$ (men 62\%; women $61 \%$ ). Attrition is described in more detail elsewhere [20,39]. 
The data were weighted based on gender, age and region of residence. Respondents who were allowed to gamble legally ( $\geq 18$ years) and who had gambled during the past year were included in the study $(n=3555)$.

\section{Gambling expenditure}

Gambling expenditure (GE) was inquired with the question: 'Roughly how much money do you spend on gambling in a typical week $(€)$ ?'. If the respondent did not gamble each week, the interviewer was instructed to advise the respondent to give an estimate of their spending when they did gamble. In this study, GE was examined using two measures: weekly gambling expenditure in euros $(€)$ and relative gambling expenditure (\%).

Weekly gambling expenditure (WGE) was rescaled if respondents indicated an overall gambling frequency of less than once a week using the formula WGE $=F^{*} \mathrm{GE} /$ $365.25 * 7$ [7-8], where

a) $F=30$ if past-year gambling frequency was $2-3$ times a month

b) $\mathrm{F}=12$ if past-year gambling frequency was once a month

c) $\mathrm{F}=6$ if past-year gambling frequency was less than monthly

For weekly gamblers WGE $=\mathrm{GE}$.

Relative gambling expenditure (RGE) was calculated using WGE and 2014 register data on personal net income provided by Statistics Finland. Personal net income consisted of total gross income (wages and salaries, investment income, benefits and allowances) minus taxes. The relative expenditure measure was formed by estimating yearly expenditure (WGE/7*365.25) and dividing it by personal net income. RGE thus represented the percentage of income used on gambling. For 361 participants it was not possible to calculate relative expenditure either because their net income was 0 euros $(n=12)$, or they did not report their gambling expenditure $(n=353)$.

\section{Gambling participation}

Participants were asked whether they had gambled on 18 predefined game types during the past 12 months (yes/ no). These game types were recoded into 12 game types because of the small size of groups among certain game types and to limit the number of variables added to the model. The recoded game types were: weekly lottery games, fast-paced daily lottery games (such as instant e-lotteries and e-Bingo), low-paced daily lottery games (such as Keno), scratch cards, betting games (including betting several teams at once, fixed odds betting, correct score and live betting) and casino games (live casino games in a casino or table games, such as roulette or Black jack run by a croupier outside a casino). Game types also included slot machines, horse race betting and private betting. Online poker included poker on the FSMA website; on the website of a private gaming company Ålands Penningautomatförening (PAF), while non-poker games on the FSMA online casino were treated as a separate game type. Finally, non-monopoly gambling included non-poker gambling outside the Finnish monopoly system, including non-monopoly and PAF games both online and on ferries between Finland, Estonia and Sweden.

Then, the number of game types played was calculated and recoded into four categories, since the association between gambling expenditure and number of game types was not linear. Also, we wanted to have estimates for different numbers of game types instead of only one estimate for a continuous variable. A cutoff of four or more games types was used to create roughly equal sized groups. Furthermore, there was a clear increase in the proportion of problem gamblers between gamblers with three and four game types (3.9 and 7.4\%), and this cutoff point has been associated with problem gambling [20]. Overall gambling frequency was calculated based on the game type in which the gambler was most active. Then, gambling frequency was also recoded: at least once a week, 1 to 3 times a month and less often than once a month.

Following the example of previous studies [40, 41], gambling mode was classified as online gambling if the person had gambled online during the past year. Online gamblers included gamblers who may have participated in land-based gambling. The rest of the responses were classified as land-based gambling only.

\section{Weekly gambling}

Game types were categorized by distinguishing active gamblers ('at least once a week') and more occasional gamblers ('less than once a week') and 'non-players. This classification was used to assess the added effect of frequent gambling on 12 game types on gambling expenditure when controlling for overall gambling frequency.

\section{Data analysis}

Two separate multiple log-linear regression models were used to explain the variation of WGE and RGE, since the distributions of both dependent variables were skewed to the right. In both models the independent variables were gender, age group, education level (demographic variables), overall gambling frequency, number of game types played and gambling mode (participation factors). Additionally, the nine game types were entered into the models using a stepwise forward method to find out which specific game types contributed to explaining WGE and RGE after controlling for demographics and participation factors. Casino games, non-poker games on the FSMA online casino and private gambling were 
excluded before stepwise regression because of the small group size of weekly gamblers. Exponentiations of beta coefficients $(\exp (\beta))$ were interpreted as percentage differences between a subcategory and a reference category. WGE and RGE means were calculated separately for each of the nine game types by gambling frequency, and means were presented in two figures for the whole data and by number of game types (1-2 game types vs. at least three game types). If there were less than three respondents in a subcategory the corresponding mean was rounded to lower disclosure risk. All analyses were weighted based on gender, age and region of residence. Log-linear regression analysis was conducted using SPSS version 23.0 and the mean figures were constructed using R [42].

\section{Results}

\section{Demographics}

Nearly half (46.2\%) of the 3555 respondents were women (Table 1). The respondents' mean age was 48.38 years. Most participants had basic vocational qualifications $(33.4 \%)$ or a higher degree (42.9\%).

\section{Weekly gambling}

The different game types differed in popularity (Table 2). More than one-third (37.8\%) of the gamblers played lottery games on a weekly basis. The second most common game types played on a weekly basis were low-paced daily lottery games $(9.3 \%)$, slot machines $(7.1 \%)$ and betting games $(5.0 \%)$.

\section{Models explaining WGE and RGE}

WGE was available for 3202 respondents and averaged $9.71 € /$ week (SD 43.72). RGE was available for 3194 respondents and averaged $3.0 \%$ of personal net income (SD 12.73). Using the stepwise forward method, eight game type variables were included in the models; only fast-paced lottery games were excluded. The models explained the higher amount of weekly expenditure $\left(\mathrm{x}^{2}\right.$ $(33)=3716.19, p<.001)$ and relative gambling expenditure $\left(\mathrm{X}^{2}(33)=3314.94, \mathrm{p}<.001\right)$ statistically significantly (Table 3). Males' weekly spending was $39 \%$ higher than females', and relative to their annual net income $22 \%$ higher than females' spending. Age also had an effect on both expenditure measures. Almost all age groups spent less on gambling than persons aged 65-74. Relative to personal net income, however, gamblers under 25 spent 79\% more than those aged 65-74. The effect of education level on both expenditure measures was reversed as almost all education groups spent more on gambling than those with the highest education level (Master's or equivalent). Relative to their personal net income, those who had a lower secondary education or
Table 1 Demographics and factors related to gambling participation

\begin{tabular}{|c|c|c|}
\hline & $\%$ & $\mathrm{~N}$ \\
\hline \multicolumn{3}{|l|}{ Gender } \\
\hline Woman & 46.2 & 1644 \\
\hline Man & 53.8 & 1911 \\
\hline \multicolumn{3}{|l|}{ Age group } \\
\hline $18-24$ & 9.1 & 325 \\
\hline $25-34$ & 14.9 & 529 \\
\hline $35-44$ & 15.8 & 563 \\
\hline $45-54$ & 18.3 & 649 \\
\hline $55-64$ & 22.7 & 806 \\
\hline $65-74$ & 19.2 & 683 \\
\hline \multicolumn{3}{|l|}{ Education level } \\
\hline Up to lower secondary education & 15.2 & 542 \\
\hline Upper secondary & 7.9 & 281 \\
\hline Basic vocational qualification & 33.4 & 1188 \\
\hline Short cycle tertiary education & 16.6 & 591 \\
\hline Bachelor's or equivalent & 14.9 & 530 \\
\hline Master's or equivalent & 11.4 & 407 \\
\hline Missing & 0.5 & 16 \\
\hline \multicolumn{3}{|l|}{ Overall gambling frequency } \\
\hline Less often than monthly & 27.5 & 979 \\
\hline 1 to 3 times a month & 27.4 & 975 \\
\hline Weekly or more often & 45.0 & 1600 \\
\hline \multicolumn{3}{|l|}{ Number of game types } \\
\hline 1 & 29.6 & 1051 \\
\hline 2 & 26.8 & 953 \\
\hline 3 & 17.3 & 616 \\
\hline 4 or more & 26.3 & 935 \\
\hline \multicolumn{3}{|l|}{ Gambling mode } \\
\hline Strictly land-based & 71.4 & 2539 \\
\hline Online & 28.69 & 1016 \\
\hline Total & 100 & 3555 \\
\hline
\end{tabular}

Weighted based on gender, age and region of residence ( $\mathrm{N}=3555$, non-weighted)

less spent nearly three times more than their highly educated counterparts.

All participation factors had an effect on expenditure. Those who gambled once a week or more spent 14 times more than those who only gambled rarely and 16 times more relative to their personal net income. Engaging in four or more game types increased weekly expenditure and relative expenditure by 52 and $62 \%$, respectively, compared to those who played one game type. Gambling online increased weekly expenditure by just $10 \%$ and was not statistically significantly associated with relative gambling expenditure. 
Table 2 Weekly gambling by game types

\begin{tabular}{|c|c|c|}
\hline & $\%$ & $\mathbf{N}$ \\
\hline \multicolumn{3}{|l|}{ Weekly lottery games ${ }^{a}$} \\
\hline non-player & 11.5 & 408 \\
\hline less than once a week & 50.7 & 1802 \\
\hline at least once a week & 37.8 & 1344 \\
\hline \multicolumn{3}{|c|}{ Fast-paced daily lottery games ${ }^{a}$} \\
\hline non-player & 92.3 & 3282 \\
\hline less than once a week & 7.1 & 252 \\
\hline at least once a week & 0.6 & 21 \\
\hline \multicolumn{3}{|c|}{ Low-paced daily lottery games ${ }^{a}$} \\
\hline non-player & 72.2 & 2566 \\
\hline less than once a week & 18.4 & 655 \\
\hline at least once a week & 9.3 & 332 \\
\hline \multicolumn{3}{|l|}{ Scratch cards ${ }^{a}$} \\
\hline non-player & 47.3 & 1680 \\
\hline less than once a week & 50.8 & 1805 \\
\hline at least once a week & 2.0 & 70 \\
\hline \multicolumn{3}{|l|}{ Betting games $^{a}$} \\
\hline non-player & 82.3 & 2925 \\
\hline less than once a week & 12.7 & 452 \\
\hline at least once a week & 5.0 & 178 \\
\hline \multicolumn{3}{|l|}{ Casino games $^{\mathrm{a}}$} \\
\hline non-player & 91.8 & 3265 \\
\hline less than once a week & 8.0 & 285 \\
\hline at least once a week & 0.1 & 5 \\
\hline \multicolumn{3}{|l|}{ Slot machines ${ }^{a}$} \\
\hline non-player & 65.0 & 2309 \\
\hline less than once a week & 27.9 & 993 \\
\hline at least once a week & 7.1 & 253 \\
\hline \multicolumn{3}{|l|}{ Horse games ${ }^{a}$} \\
\hline non-player & 93.0 & 3306 \\
\hline less than once a week & 5.6 & 200 \\
\hline at least once a week & 1.4 & 49 \\
\hline \multicolumn{3}{|l|}{ Private betting } \\
\hline non-player & 95.2 & 3383 \\
\hline less than once a week & 4.7 & 168 \\
\hline at least once a week & 0.1 & 4 \\
\hline \multicolumn{3}{|l|}{ Online poker ${ }^{a, b, c}$} \\
\hline non-player & 96.5 & 3430 \\
\hline less than once a week & 3.0 & 106 \\
\hline at least once a week & 0.5 & 19 \\
\hline \multicolumn{3}{|c|}{ Non-poker games on FSMA online casino ${ }^{a}$} \\
\hline non-player & 98.1 & 3489 \\
\hline less than once a week & 1.7 & 60 \\
\hline at least once a week & 0.2 & 6 \\
\hline
\end{tabular}

Table 2 Weekly gambling by game types (Continued)

\begin{tabular}{lll}
\hline & $\%$ & N \\
\hline Non-monopoly gambling & & \\
non-player & 85.7 & 3046 \\
less than once a week & 13.6 & 484 \\
at least once a week & 0.7 & 25 \\
Total & 100 & 3555 \\
\hline
\end{tabular}

Weighted based on gender, age and region of residence $(\mathrm{N}=3555$, nonweighted). ${ }^{a}$ Finnish gambling monopoly games; ${ }^{\mathrm{b}} \mathrm{PAF}$, Ålands Penningautomatförening's games; ' ${ }^{\circ}$ Gambling internationally outside the Finnish gambling monopoly. FSMA Finland's Slot Machine Association

Those who played non-monopoly games at least once a week had a four times higher expenditure and a three-and-a-half times higher relative expenditure than gamblers who did not play abroad. Other game types where weekly gambling had an effect on expenditure measures were low-paced daily lottery games, scratch games, betting games, slot machines, horse race betting and online poker, where weekly gamblers had a $31-155 \%$ higher expenditure than the corresponding non-players.

\section{WGE and RGE by game types}

Those who played non-monopoly games had the highest mean WGE (146.84 €/week) among weekly gamblers (Fig. 1). Other game types with high mean WGE were online poker (59.61 €/week), scratch games (51.77 $€ /$ week) and horse race betting (48.67 €/week). RGE means were highest among those who gambled weekly non-monopoly games (30.63\%), scratch games (14.77\%), betting games (14.20\%) and online poker (13.65\%) (Fig. 2).

Fast-paced daily lottery games $(n=2)$, scratch games $(n=9)$, horse race betting $(n=5)$, online poker $(n=1)$ and non-monopoly gambling $(n=0)$ had less than 10 weekly gamblers who gambled only one or two game types (Figs. 1-2). Among those who gambled only one or two game types, the highest WGE and RGE means were recorded for horse race betting and other betting games. WGE and RGE means were lower for those who played one or two game types compared to the corresponding means for all gamblers, except for horse race betting (WGE means $53.40 € /$ week vs. $48.67 € /$ week and RGE means $15.50 \%$ vs. $11.02 \%$ ) and betting games (RGE means $19.16 \%$ vs. $14.20 \%$ ). The WGE and RGE means for those who played at least three game types weekly were similar to the corresponding means for all gamblers.

\section{Discussion}

Male gender, lower education level, higher gambling frequency and higher number of game types increased both WGE and RGE, which is in line with previous research (e.g. [20-22]). Our results also indicated that younger 
Table 3 Multiple log-linear regression models explaining weekly and relative gambling expenditure

\begin{tabular}{|c|c|c|c|c|}
\hline & \multicolumn{2}{|c|}{ Weekly gambling expenditure $(€)$} & \multicolumn{2}{|c|}{ Relative gambling expenditure (\%) } \\
\hline & $\exp (\beta)$ & $95 \% \mathrm{Cl}$ & $\exp (\beta)$ & $\mathrm{Cl} 95 \% \mathrm{Cl}$ \\
\hline \multicolumn{5}{|l|}{ Gender } \\
\hline Female & 1.0 & & 1.0 & \\
\hline Male & $1.39 * * *$ & $1.28-1.50$ & $1.22^{* * *}$ & $1.12-1.34$ \\
\hline \multicolumn{5}{|l|}{ Age group } \\
\hline $65-74$ & 1.0 & & 1.0 & \\
\hline $55-64$ & 0.97 & $0.87-1.08$ & 0.89 & $0.79-1.01$ \\
\hline $45-54$ & 0.90 & $0.80-1.01$ & $0.77^{* * *}$ & $0.67-0.88$ \\
\hline $35-44$ & $0.87^{*}$ & $0.76-0.99$ & $0.76^{* * *}$ & $0.65-0.88$ \\
\hline $25-34$ & $0.74^{* * *}$ & $0.64-0.85$ & 0.86 & $0.73-1.01$ \\
\hline $18-24$ & $0.69 * * *$ & $0.59-0.82$ & $1.79 * * *$ & $1.48-2.16$ \\
\hline \multicolumn{5}{|l|}{ Education level } \\
\hline Master's or equivalent & 1.0 & & 1.0 & \\
\hline Bachelor's or equivalent & $1.32^{* * *}$ & $1.14-1.53$ & $1.66^{* * *}$ & $1.41-1.95$ \\
\hline Short cycle tertiary education & $1.40 * * *$ & $1.21-1.61$ & $1.96^{* * *}$ & $1.67-2.30$ \\
\hline Basic vocational qualification & $1.48^{* * *}$ & $1.30-1.68$ & $2.20 * * *$ & $1.90-2.54$ \\
\hline Upper secondary & 1.17 & $0.98-1.40$ & $1.97^{* * *}$ & $1.61-2.40$ \\
\hline Up to lower secondary education & $1.48^{* * *}$ & $1.28-1.72$ & $2.88^{* * *}$ & $2.43-3.41$ \\
\hline \multicolumn{5}{|l|}{ Overall gambling frequency } \\
\hline Rarely than monthly & 1.0 & & 1.0 & \\
\hline $1-3$ times a month & $4.68^{* * *}$ & $4.21-5.20$ & $5.00 * * *$ & $4.44-5.63$ \\
\hline Once a week or more & $14.20^{* * *}$ & $11.91-16.93$ & $16.22^{* * *}$ & $13.29-19.78$ \\
\hline \multicolumn{5}{|l|}{ Number of game types } \\
\hline 1 & 1.0 & & 1.0 & \\
\hline 2 & 1.06 & $0.93-1.19$ & 1.07 & $0.93-1.23$ \\
\hline 3 & $1.24^{*}$ & $1.05-1.47$ & $1.32^{* *}$ & $1.08-1.60$ \\
\hline 4 or more & $1.52^{* *}$ & $1.19-1.94$ & $1.62^{* *}$ & $1.23-2.13$ \\
\hline \multicolumn{5}{|l|}{ Gambling mode } \\
\hline Strictly land-based & 1.0 & & 1.0 & \\
\hline Online & $1.10^{*}$ & $1.00-1.20$ & 1.01 & $0.92-1.12$ \\
\hline \multicolumn{5}{|l|}{ Weekly lottery games } \\
\hline Non-player & 1.0 & & 1.0 & \\
\hline Less than once a week & 0.88 & $0.76-1.01$ & $0.67^{* * *}$ & $0.56-0.79$ \\
\hline At least once a week & 1.17 & $0.97-1.42$ & 0.83 & $0.67-1.03$ \\
\hline \multicolumn{5}{|l|}{ Low-paced daily lottery games } \\
\hline Non-player & 1.0 & & 1.0 & \\
\hline Less than once a week & 1.08 & $0.97-1.21$ & 1.03 & $0.91-1.17$ \\
\hline At least once a week & $1.67^{* * *}$ & $1.44-1.93$ & $1.62^{* * *}$ & $1.37-1.91$ \\
\hline \multicolumn{5}{|l|}{ Scratch games } \\
\hline Non-player & 1.0 & & 1.0 & \\
\hline Less than once a week & 0.99 & $0.89-1.10$ & 0.91 & $0.81-1.03$ \\
\hline At least once a week & $1.79 * * *$ & $1.37-2.33$ & $1.44^{*}$ & $1.07-1.94$ \\
\hline \multicolumn{5}{|l|}{ Betting games } \\
\hline Non-player & 1.0 & & 1.0 & \\
\hline
\end{tabular}


Table 3 Multiple log-linear regression models explaining weekly and relative gambling expenditure (Continued)

\begin{tabular}{|c|c|c|c|c|}
\hline & \multicolumn{2}{|c|}{ Weekly gambling expenditure $(€)$} & \multicolumn{2}{|c|}{ Relative gambling expenditure (\%) } \\
\hline & $\exp (\beta)$ & $95 \% \mathrm{Cl}$ & $\exp (\beta)$ & $\mathrm{Cl} 95 \% \mathrm{Cl}$ \\
\hline Less than once a week & $1.20^{* *}$ & $1.05-1.36$ & $1.16^{*}$ & $1.01-1.34$ \\
\hline At least once a week & $1.78^{* * *}$ & $1.49-2.12$ & $1.80^{* * *}$ & $1.47-2.20$ \\
\hline \multicolumn{5}{|l|}{ Slot machines } \\
\hline Non-player & 1.0 & & 1.0 & \\
\hline Less than once a week & $0.84^{* *}$ & $0.75-0.95$ & $0.83^{* *}$ & $0.73-0.94$ \\
\hline At least once a week & $1.31 * *$ & $1.10-1.56$ & $1.43^{* * *}$ & $1.18-1.74$ \\
\hline \multicolumn{5}{|l|}{ Horse games } \\
\hline non-player & 1.0 & & 1.0 & \\
\hline less than once a week & 1.09 & $0.93-1.27$ & 1.08 & $0.91-1.30$ \\
\hline at least once a week & $2.46^{* * *}$ & $1.82-3.31$ & $2.55^{* * *}$ & $1.82-3.57$ \\
\hline \multicolumn{5}{|l|}{ Online poker } \\
\hline non-player & 1.0 & & 1.0 & \\
\hline less than once a week & $1.27^{*}$ & $1.03-1.58$ & 1.24 & $0.97-1.58$ \\
\hline at least once a week & $1.83^{*}$ & $1.13-2.97$ & $1.79 *$ & $1.03-3.09$ \\
\hline \multicolumn{5}{|l|}{ Non-monopoly gambling } \\
\hline non-player & 1.0 & & 1.0 & \\
\hline less than once a week & 1.06 & $0.94-1.19$ & 1.03 & $0.89-1.18$ \\
\hline at least once a week & $4.09 * * *$ & $2.68-6.25$ & $3.59 * * *$ & $2.23-5.79$ \\
\hline
\end{tabular}

Weighted based on gender, age and region of residence ( $N=3202$ in WGE model and $N=3194$ in RGE model). Significance probabilities ${ }^{*} p<.05 ; * *<.01$; *** $p<.001$

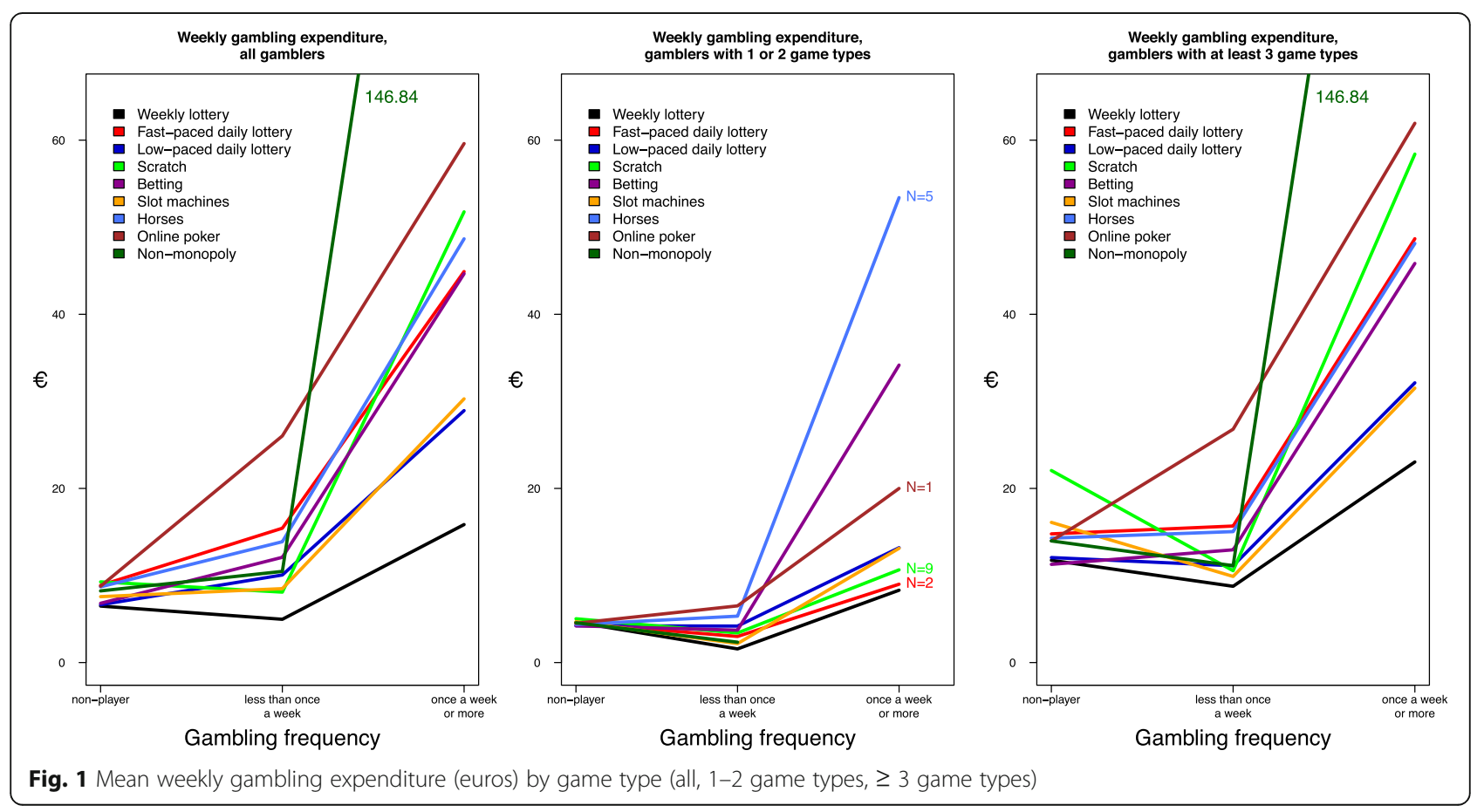




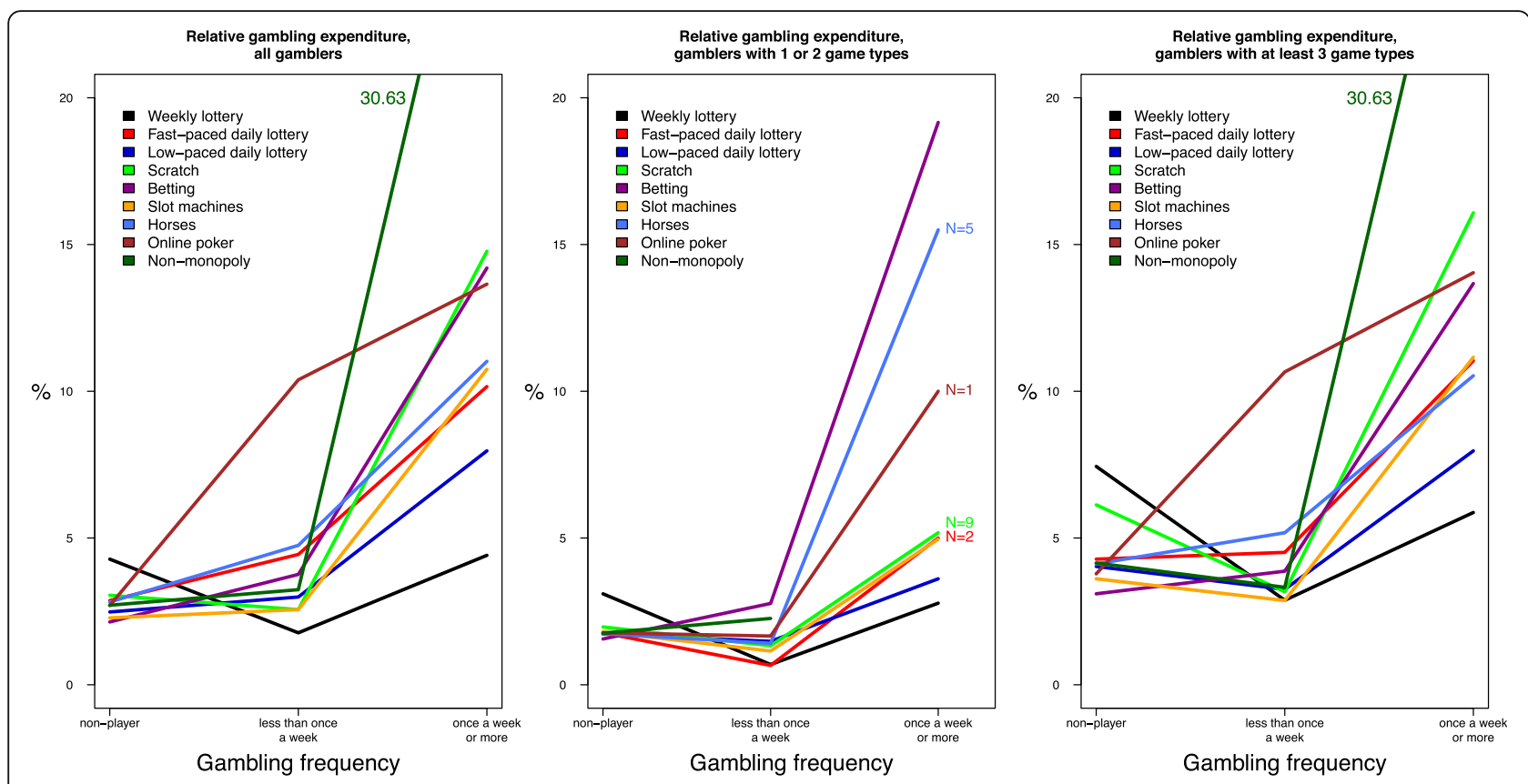

Fig. 2 Mean relative gambling expenditure (\%) by game type (all, 1-2 game types, $\geq 3$ game types)

age decreased WGE, but increased RGE. This may be partly explained by lower overall income, since low income in general $[15,16]$ is a risk factor for excessive gambling it can be seen as possibly posing greater harm to this specific age group, such as indebtedness that may in turn increase harmful gambling.

Overall gambling frequency was the strongest explanatory factor of both WGE and RGE, which supports the results of previous research [9]. Weekly horse race betting, non-monopoly gambling and online poker had the greatest increasing effect on expenditure, but scratch games, betting games and daily low-paced lottery games also contributed significantly to overall expenditure. Furthermore, betting games and online poker were associated with higher expenditure even when they were played less often than weekly. Our results suggest, in certain circumstances high WGE on these particular game types may be seen as indicators of unhealthy gambling involvement, as has been previously suggested (e.g. $[9,10])$.

Some studies indicate, that sports betting is associated with problem gambling $[8,45]$ while some studies indicate that it is not $[7,10]$. Sports betting and poker can be viewed as a lifestyle practice, often a regular feature of social interaction and leisure time [43]. Gamblers may be inclined to take unnecessary risks to demonstrate their "knowledge" of the game and enhance their social esteem. The unique feature of sports betting and poker is competition [43]. Game providers should avoid targeting this group with advertisements that create false notions of expertise [27]. Furthermore, a recent Australian study examined the risk factors for low risk gambling, moderate risk gambling and problem gambling amongst sports betters [44]. Their results indicate, that gambling expenditure, number of accounts with different operators, number of different types of promotions used and gambler's impulsiveness were significantly higher for all above mentioned risk groups, while age, gender, some normative factors, and particular sports betting variables only applied to those with the highest level of gambling-related problems. These results suggest, that when assessing risk factors for problematic gambling, severity of gambling should be taken into account, when possible, thus different levels of gambling problems should be assessed separately when possible.

Weekly gambling outside the Finnish gambling monopoly had the greatest increasing effect on gambling expenditure. This result must be interpreted with caution, however, since there was only a small number of weekly non-monopoly gamblers. Non-monopoly gamblers tend to be heavy consumers of several game types $[5,6,45]$, including monopoly games. In addition, non-monopoly gambling remains as a somewhat indefinite game type category, since it may, in fact, include any number of game types, as well as, any number of player accounts with different international gaming operators. Therefore, it may represent merely a time spent on gambling rather than a certain game type.

Frequent playing of several games is associated with gambling problems $[7,9,10]$. In addition, online problem gamblers are often mixed-mode gamblers who play multiple types of games [47-49]. The major justification 
for the Finnish gambling monopoly is that it has the potential to reduce gambling harms, and the updated Lotteries Act furthermore places emphasis on prevention [38]. As in many other countries, Finnish gambling operators have in recent years been working to develop tools for responsible gambling (RG). Recent Finnish surveys indicate that RG tools are used quite rarely and that gamblers' awareness about these tools must be improved $[11,12]$.

One of the games that increased gambling expenditure was weekly horse race betting. Based on register data provided by gambling operators, a typical gambler is a middle-age man who gambles seven times a month, spending on average 33 euros a day when gambling [22]. In Finland, online horse race betting seems to be concentrated: most gamblers spend rather small amounts of money, but there is a small group of active bettors who contribute a large proportion of total turnover [22]. Participation and interest in horse racing and betting seems to be a social cross-generational process [50], which is not the case with other types of betting. LaPlante and colleagues studied gambling problems, type of gambling and gambling involvement and noticed that the relationship between both horse race betting and private betting and problem gambling changed when gambling involvement factors were adjusted for [9]. In other words, gambling only these two particular betting games seemed to protect gamblers from problems $[7,9]$. In fact, they suggest that engaging in game types including peers might encourage control and preclude excessive gambling [9], which is opposite to the findings for sports betting [43].

Weekly lottery games were not associated with high expenditure, but daily lottery games were. Weekly lottery games are slow pace and sometimes perceived as a 'soft' type of game [4], or indeed not even viewed as a form of gambling at all [51]. Nevertheless, there are some addictive features of lottery games that are salient to the psychology of lottery gambling [52]. Recent developments of lottery games have extended gambling frequency from weekly to biweekly and daily gambling, but also changed their geography from regional or national to transnational and gambling mode from land-based to online platforms. These changes have increased the addictiveness of this game type. We suggest that future studies should make a clear distinction between different types of lottery games.

Finland has one of the highest per capita numbers of slot machines in Europe. In our model, weekly slot machine gambling was also associated with higher expenditure, but it was not among the most significant game types. Slot machine gambling is nevertheless associated with gambling-related harms [7, 8, 38, 43, 45]. Moreover, based on the national helpline Peluuri, the primary game types that cause problems among Finnish gamblers are
EGMs (69\%), betting games (9\%), poker (5\%) and casino games (5\%) [53]. On the other hand, some studies indicate that slot machines are not among the top five game types associated with problem gambling $[4,10]$.

The results provide useful information about gambling expenditure patterns by game type. At the same time, they underscore the fact that gambling participation needs to be studied in its entirety. This was particularly clear in Figs. 1, 2, which showed that for those gambling at least three game types weekly, WGE and RGE means were similar to the corresponding means for all gamblers. Gambler profiles can be grouped based on gambling participation and the combination of different game types played $[46,54]$. A study on gambling clusters indicates that gambling on slot machines, sports betting and playing multiple games are the strongest indicators of gambling problems [46]. These clusters provide useful leads for future studies on game types and gambling expenditure.

There is evidence that high gambling expenditure is associated with gambling-related harms $[18,31,46,55$, 56]. However, we still have an incomplete picture of what level of expenditure indicates harms. A Finnish study that used the South Oaks Gambling Screen [57] indicates that on average, problem gamblers spend $11.8 \%$, probable pathological gamblers spend $17.3 \%$, and non-problem gamblers spend $1.6 \%$ of their monthly net income on gambling [15]. Gender differences have also been reported in the relative amount of income associated with problematic gambling in Finland [16].

\section{Study limitations}

Phrasing of the question and response instructions matter when inquiring about gambling expenditure $[58,59]$. In our study, was inquired by one question instead of assessing it separately for each game types, and gambling expenditure was not explained in the instructions for the respondents. Furthermore, game types were inquired using a list of available game types provided by different operators. These gaming providers have their own RG tools, but we were unable control for the use of these tools. Furthermore, the number of games varies in different game type categories. Moreover, specific game types may be played more frequently than others due to the nature of the games [60]. For example, it is quite rare that live casino games are played on a weekly basis. In our study, however, live casino games included table games such as roulette and Blackjack run by a croupier outside a casino. PAF games on cruise ferries are rarely, if ever, played on a weekly basis. Weekly non-monopoly gambling therefore mainly reflect non-monopoly online gambling. The game type list which includes several gambling modes and game characteristics can create overlapping categories [18]. Furthermore, there is the 
possibility of incomplete coverage, meaning that some game types are assessed by subtypes and others are not [18]. For example, betting games were divided into horse games and other types of betting, and three subtypes of lottery games were identified.

Overall, gamblers frequently underestimate their losses [59, 61-65]. Despite this, it has been shown that self-reported gambling losses correlate with register-based losses. Gamblers with higher losses, however, tend to have more difficulty estimating their gambling expenditure [64, 65]. A high intensity of play, problem gambling and the type of game gambled may also cause estimation bias. People who play games that carry a social stigma (such as EGMs) may underestimate their expenditure [59]. Furthermore, self-reported losses have proved to be more accurate when using a 3-month rather than a 12-month time frame [64]. Our results therefore give an estimation of overall expenditure. One of strengths of this study is its high response rate.

\section{Conclusions}

Gambling frequency was the strongest indicator of high expenditure, as also suggested in previous studies $[7,9]$. However, this study provides some useful information about gambling expenditure patterns by game type. Different game types had different effect sizes on gambling expenditure, and we identified several games types that increase both WGE and RGE. Weekly gambling on horse races and non-monopoly games had the greatest increasing effect on expenditure. Great effort should be made by game providers and policy makers to inform individuals about these particular games and possible harms related to them. In addition, betting games, sports betting and online poker in particular, were associated with higher expenditure even when they were played less often than weekly. Similarly, more active harm-minimizing initiatives are recommended particularly for sports bettors and online poker players. However, different game types also varied according to their popularity, and therefore the extent of potential harms caused by high expenditure also varies on the population level. Studies of gambling problems have found that few gamblers play at high-risk levels, but large proportions gamble at low-risk levels $[31,66,67]$. Therefore, in order to prevent and reduce gambling-related harms, lower risk gamblers should also be targeted in preventive actions. Based on our results, future prevention and harm minimization efforts should be tailored to different game types for greater effectiveness.

\section{Abbreviations}

EGM: Electronic Gaming Machine; FSMA: Finland's Slot Machine Association PAF: Ålands Penningautomatförening; RGE: Relative gambling expenditure; WGE: Weekly gambling expenditure

\section{Acknowledgements}

The authors wish to thank Mr. David Kivinen for revising the language of this paper.

\section{Funding}

This research was funded by the Ministry of Social Affairs and Health, Helsinki, Finland (section 52 of the Appropriation of the Lotteries Act). However, the Ministry had no role in the study design, analysis or interpretation of the results nor in any phase of the publication process.

\section{Availability of data and materials}

The Finnish gambling 2015 dataset is available from the Finnish Social Science Data Archive (http://www.fsd.uta.fi/en/).

\section{Authors' contributions \\ AHS, JK, RP and SC were responsible for the study conception and design; SC \& AS conducted literature searches and provided summaries of previous research studies. JK and RP performed the analysis; AHS, JK, RP, and SC were responsible for the interpretation of the data and manuscript preparation; HA made critical revisions to the paper for important intellectual content; all authors read and approved the final version.}

\section{Ethics approval and consent to participate}

The survey was conducted in accordance with the ethical standards of the Declaration of Helsinki. The Ethics Committee of the National Institute for Health and Welfare, Finland, approved the research protocol (THL/1122/ 6.02.01/2014). Potential participants received written and verbal information about the study and the principles of voluntary participation. Verbal informed consent was obtained from all participants. Permission to use the register data was obtained from Statistics Finland.

\section{Competing interests}

The authors do not hold any position, receive ongoing or significant funding, and are not engaged in any business or with any organization that creates a real or perceived conflict of interest in their work on this manuscript.

\section{Publisher's Note}

Springer Nature remains neutral with regard to jurisdictional claims in published maps and institutional affiliations.

\section{Author details}

${ }^{1}$ Alcohol, Drugs and Addictions Unit, National Institute for Health and Welfare, P.O. Box 30, FI-00271 Helsinki, Finland. 'Faculty of Health Sciences, University of Eastern Finland, Kuopio, Finland. ${ }^{3}$ Public Health Evaluation and Projection Unit, National Institute for Health and Welfare, Helsinki, Finland. ${ }^{4}$ Abdominal Center, University and University Hospital of Helsinki, Helsinki, Finland. ${ }^{5}$ Department of Psychology and Speech-Language Pathology, Faculty of Social Sciences, University of Turku, Turku, Finland.

Received: 28 June 2017 Accepted: 25 May 2018

Published online: 05 June 2018

\section{References}

1. Browne M, Langham E, Rawat V, Greer N, Li E, Rose J, Rockloff M, Donaldson P, Thorne H, Goodwin B, Bryden G, Best T. Assessing gambling-related harm in Victoria: a public health perspective. Melbourne: Victorian Responsible Gambling Foundation; 2016. https://www.responsiblegambling.vic.gov.au/_ data/assets/pdf_file/0007/28465/Browne_assessing_gambling-related_ harm_in_Vic_Apr_2016-REPLACEMENT2.pdf

2. Langham E, Thorne H, Browne M, Donaldson P, Rose J, Rockloff M. Understanding gambling related harm: a proposed definition, conceptual framework and taxonomy of harms. BMC Public Health. 2016;16:80. https:// doi.org/10.1186/s12889-016-2747-0.

3. Dowling N, Smith D, Omas T. Electronic gaming machines: are they the 'crack-cocaine' of gambling? Addiction. 2005;100(1):33-45.

4. Binde P. What are the most harmful forms of gambling? Analyzing problem gambling prevalence surveys CEFOS Working Paper 12, 2011.

5. Auer M, Griffiths M. Voluntary limit setting and player choice in most intense online gamblers: an empirical study of gambling behavior. J Gambl Stud. 2013;29(4):647-60. 
6. Afifi TO, Cox BJ, Martens PJ, Sareen J, Enns MW. The relation between types and frequency of gambling activities and problem gambling among women in Canada. Can J Psychiatry. 2010;55(1):21-8.

7. Binde $P$, Romild U, Volberg R. Forms of gambling, gambling involvement and problem gambling: evidence from a Swedish population survey. Int Gambl Stud. 2017;17:3,490-507. https://doi.org/10.1080/14459795.2017.1360928.

8. Abbott M, Stone CA, Billi R, Yeung K. Gambling and problem gambling in Victoria, Australia: changes over 5 years. J Gambl Stud. 2016;32:1,47-78.

9. LaPlante DA, Nelson SE, LaBrie RA, Shaffer HJ. The relationships between disordered gambling, type of gambling, and gambling involvement in the British gambling prevalence survey 2007. Eur J Public Health. 2009;21(4): 532-7. https://doi.org/10.1093/eurpub/ckp177

10. Welte JW, Barnes GM, Tidwell MO, Hoffman JH. The Association of form of gambling with problem gambling among American youth. Psychol Addict Behav. 2009;23(1):105-12.

11. Salonen A, Latvala T, Castrén S, Selin J, Hellman M. Rahapelikysely 2016. Rahapelaaminen, rahapelihaitat ja rahapelien markkinointiin liittyvät mielipiteet Uudellamaalla, Pirkanmaalla ja Kymenlaaksossa [Gambling Harms Survey 2016. Gambling, gambling-related harm and opinions on gambling marketing in Uusimaa, Pirkanmaa and Kymenlaakso.] National Institute for Health and Welfare (THL). Report 9/2017. Helsinki, Finland 2017.

12. Salonen A, Castrén S, Latvala T, Heiskanen M, Alho H. Rahapelikysely 2016. Rahapelaaminen, rahapelihaitat ja rahapelien markkinointiin liittyvät mielipiteet rahapeliongelmaan apua hakevilla Peliklinikan asiakkailla [Gambling Harms Survey 2016. Gambling, gambling-related harm and opinions on gambling marketing among Gambling Clinic clients]. National Institute for Health and Welfare (THL). Report 8/2017. Helsinki, Finland 2017.

13. Browne M, Bellringer M, Greer N, Kolandai-Matchett K, Rawat V, Langham E, Rockloff M, Palmer Du Preez K, Abbott M. Measuring the burden of gambling harm in New Zealand. Wellington: Ministry of Health; 2017.

14. Shannon K, Anjoul F, Blaszczynski A. Mapping the proportional distribution of gambling-related harms in a clinical and community sample. Int Gambl Stud. 2017;17(3):366-85. https://doi.org/10.1080/14459795.2017.1333131.

15. Salonen AH, Kontto J, Alho H, Castren S. Suomalaisten rahapelikulutus keneltä rahapeliyhtiöiden tuotot tulevat? [Gambling consumption in Finland who generate gambling operators' revenues?.]. Yhteiskuntapolitiikka. 2017; 82(5):549-59.

16. Castren $\mathrm{S}$, Kontto J, Alho H, Salonen $\mathrm{AH}$. The relationship between gambling expenditure, socioeconomics, health-related correlates and gambling behavior - a cross-sectional population survey in Finland. Addiction, 2017; Accepted manuscript online: 1 July 2017: DOI: 10.1111/add.

17. JS, LP. Economist: The house wins daily chart. Geographic detail. Charts, maps and infographies, 2014. http://www.economist.com/blogs/ graphicdetail/2014/02/daily-chart-0. Accessed 16 Dec 2016.

18. Williams RJ, Volberg RA, Stevens RMG, Williams LA, Arthur JN. The Definition, Dimensionalization, and Assessment of Gambling Participation. Report prepared for the Canadian Consortium for Gambling Research, 2017. Accessed 1 June 2017

19. Turja T, Halme J, Mervola M, Järvinen-Tassopoulos J, Ronkainen J-E. Suomalaisten rahapelaaminen 2011. [Finnish gambling 2011] National Institute for Health and Welfare (THL). Report 14/2012. Helsinki, 2012.

20. Salonen AH, Raisamo S. Suomalaisten rahapelaaminen 2015. Rahapelaaminen, rahapeliongelmat ja rahapelaamiseen liittyvät asenteet ja mielipiteet 15-74vuotiailla. In: Finnish gambling 2015. Gambling, gambling problems, and attitudes and opinions on gambling among Finns aged 15-74. Helsinki: National Institute for Health and Welfare (THL). Report 16/2015; 2015

21. Koivula A, Koiranen I, Räsänen P. Digitalisaatio ja verkkorahapelaamisen väestöryhmittäiset muutokset 2006-2014. [Digitalization and changes in online gambling behaviours in different population groups 2006-2014.]. Yhteiskuntapolitiikka. 2016;4(81):371-83.

22. Suhonen N, Kainulainen T. Ravivedonlyöjien verkkopelaaminen Suomessa. Erot kulutus- ja pelikäyttäytymisessä sukupuolen ja iän mukaan. [Online horse race betting in Finland. An empirical study on age and gender differences in consumer and betting behaviour.]. Yhteiskuntapolitiikka. 2016; 4(81):395-406.

23. McCormack A, Shorter GW, Griffiths MD. An Empirical Study of Gender Differences in Online Gambling. J Gambl Stud. 2014;30(1):71-88. doi.org/10. 1007/s10899-012-9341-x

24. Davidson T, Rodgers B, Markham F, Taylor-Rodgers E. Gambling expenditure in the act of (2014): by level of problem gambling, type of activity, and socioeconomic and demographic characteristics. Final Report 2016.
Available at: https://www.gamblingandracing.act.gov.au/__data/assets/pdf_ file/0010/982774/2014-Gambling-Expenditure.pdf. Accessed 1 Feb 2017.

25. Worthington AC, Brown K, Crawford M, Pickernell D. Socioeconomic and demographic determinants of household gambling in Australia. Discussion paper No. 156. Brisbane Qld: School of Economics and Finance. Queensland University of Technology; 2003.

26. MacDonald M, McMullan JL, Perrier DC. Gambling households in Canada. J Gambl Stud. 2004;20(3):187-235.

27. Hing N, Lamont MJ, Vitartas P, Fink E. Sports bettors' responses to sportsembedded gambling promotions: implications for compulsive consumption. J Bus Res. 2015;68(10):2057-66.

28. Quilty LC, Murati D, Bagby RM. Identifying indicators of harmful and problem gambling in a Canadian sample through receiver operating characteristic analysis. Psyc Addict Behav. 2014;28(1):229-37.

29. Young M, Stevens M. Player preferences and social harm: an analysis of the relationships between player characteristics, gambling modes, and problem gambling. Int J Ment Health Addiction. 2009;7:262-79.

30. Hodgins DC, Schopflocher DP, Martin CR, El-Guebaly N, Casey DM, Currie SR, et al. Disordered gambling among higher-frequency gamblers: who is at risk? Psychol Med. 2012;42:2433-44. https://doi.org/10.1017/ S0033291712000724.

31. Raisamo S, Mäkelä P, Salonen AH, Lintonen T. The extent and distribution of gambling harm in Finland as assessed by the problem gambling severity index (PGSI). Eur J Pub Health. 2014:1-7. https://doi.org/10.1093/eurpub/ cku210.

32. Wood RTA, Shorter GW, Griffiths MD. Rating the suitability of responsible gambling features for specific game types: a resource for optimizing responsible gambling strategy. Int Ment Health Addiction. 2014;12:94-112

33. King DL, Gainsbury SM, Delfabbro PH, Hing N, Abarbanel B. Distiguishing between gaming and gambling activities in addiction research. J Behav Addict. 2015;4(4):215-20.

34. Stevens $M$, Young M. Who plays what? Participation profiles in chance versus skill-based gambling. J Gambl Stud. 2010;26:89-103. https://doi.org/ 10.1007/210899-009-9143.

35. Hing N, Breen $\mathrm{H}$. 'Profiling lady luck: an empirical study of gambling and problem gambling amongst female club members. J Gambl Stud. 2001; 17(1):47-69. doi.org/10.1023/A:1016640332005

36. Svensson J, Romild U, Nordenmark M, Månsdotter A. Gendered gambling domains and changes in Sweden. Int Gambl Stud. 2011;11(2):193-211. doi. org/10.1080/14459795.2011.581676

37. Edgren R, Castrén S, Alho H, Salonen AH. Gender comparison of online and land-based gamblers from a nationally representative sample: does gambling online pose elevated risk? Comput Hum Behav. 2017; https://doi. org/10.1016/j.chb. 2017.02.033.

38. Lotteries Act, 14 § 20.5.2011/575. Finlex http://www.finlex.fi/fi/laki/ajantasa/ 2001/20011047. Accessed 30 May 2017.

39. Salonen $\mathrm{AH}$, Alho $\mathrm{H}$, Castrén $\mathrm{S}$. The extent and type of gambling harms for concerned significant others: a cross-sectional population study in Finland. Scand J Public H 2016; Doi:https://doi.org/10.1177/ 1403494816673529

40. Gainsbury SM, Russell A, Hing N. An investigation of social casino gaming among land-based and Internet gamblers: A comparison of sociodemographic characteristics, gambling and co-morbidities. Computers in Human Behavior. 2014;33:126-35. doi.org/10.1016/j.chb.2014.01.031

41. Baggio S, Gainsbury SM, Berchtold A, Iglesias K. Co-morbidity of gambling and Internet use among Internet and land-based gamblers: classic and network approaches. Int Gambl Stud. 2016;16(3):500-517. doi.org/https:// doi.org/10.1080/14459795.2016.1242148.

42. R Core Team: R: A language and environment for statistical computing. $R$ Foundation for statistical Computing, Vienna, Austria 2013. Available at: http://www.R-project.org/ (Accessed 11 Sept 2016).

43. Gordon R, Gurrieri L, Chapman M. Broadening an understanding of problem gambling: the lifestyle consumption community sports betting. J Bus Res. 2015;68:2164-77.

44. Russell AMT, Hing N, Li E, Vitartas P. Gambling risk groups are not all the same: risk factors amongst sports bettors. J Gambl Stud. 2018; https://doi. org/10.1007/s10899-018-9765-z

45. Castrén S, Perhoniemi R, Kontto J, Alho H, Salonen AH. Association between gambling involvement by game type and gambling harms: Finnish population study. Int Gambl Stud DOl: https://doi.org/10.1080/14459795. 2017.1388830. 
46. Heiskanen M, Toikka A. Clustering Finnish gambler profiles based on the money and time consumed in gambling activities. J Gamb Stud. 2015 https://doi.org/10.1007/s10899-015-9556-8.

47. Wardle H, Moody A, Griffiths M, Orford J, Volberg R. Defining the online gambler and patterns of behaviour integration: evidence from the British gambling prevalence survey 2010. Int Gambl Stud. 2011;11:339-56. https:// doi.org/10.1080/14459795.2011.628684.

48. Gainsbury SM. Online Gambling Addiction: the Relationship Between Internet Gambling and Disordered Gambling. Curr Addict Rep. 2015;2:18593. https://doi.org/10.1007/s40429-015-0057-8.

49. Hing N, Russell A, Browne M. Risk factors for gambling problems on online electronic gaming machines, Race Betting and Sports Betting. Front Psychol. 2017:8:779. https://doi.org/10.3389/fpsyg.2017.00779.

50. Raento P, Härmälä L. Suomalaisen ravipelaamisen muutos 2000-luvulla. In: Raento P, editor. Rahapelaaminen Suomessa. Helsinki: Gaudeamus; 2012. p. $119-60$.

51. Wood RTA, Griffths MD. The acquisition, development and maintenance of lottery and scratch card gambling in adolescence. J Adolesc. 1998;21:26573.

52. Ariyabuddhipongs V. Lottery gambling: a review. J Gambl Stud. 2011;27:153.

53. Pajula M, Sjöholm M, Vuorento H. Peluuri vuosiraportti 2015-2016. In: Peluuri's Annual Report 2005-2016. Helsinki: Peluuri; 2017.

54. Romild U, Svensson J, Volberg R. A gender perspective on gambling clusters in Sweden using longitudinal data. Nordic Stud Alcohol Drugs 2016; 33(1):1-22. http://doi.org/https://doi.org/10.1515/nsad-2016-0004.

55. Markham F, Young M, Doran B. Gambling expenditure predicts harm: evidence from a venue-level study. Addiction. 2014;109:1509-16. https://doi. org/10.1111/add.13178

56. Markham F, Young M, Doran B. The relationship between player losses and gambling-related harm: evidence from nationally representative crosssectional surveys in four countries. Addiction (2015), doi: https://doi.org/10. 1111/add.13178.

57. Lesieur H, Blume $\mathrm{S}$. The south oaks gambling screen (SOGS) a new instrument for the identification of pathological gamblers. Am J Psychiatr. 1987;144(9):1184-8.

58. Blaszczynski A, Ladouceur R, Goulet A, Savard C. 'How much do you spend gambling?': ambiguities in questionnaire items assessing expenditure. Int Gambl Stud. 2006:6(2):123-8.

59. Wilkins R. The household income and labour dynamics in Australia survey: selected findings from waves 1-15. Melbourne institute: Applied Economic \& Social Research. The University of Melbourne: Australia, 2017. http:// melbourneinstitute.unimelb.edu.au/hilda.

60. Afifi T, LaPlante D, Tallieu T, Dowd D, Shaffer H. Gambling involvement: considering frequency of play and the moderating effects of gender and age. Int J Ment Health Addiction. 2014;12:283-94.

61. Australian Bureau of Statistics. Productivity Commission Inquiry into Australia's Gambling Industries. 1998, submission No 141. http://www.pc gov.au/inquiries/completed/gambling/submissions/sub141/sub141.pdf.

62. Williams R, Volberg R. Impact of survey description, administration method, and exclusionary criteria on population prevalence rates on problem gambling. Int Gambl Stud. 2009;9(2):101-17.

63. Williams R, Volberg R. Best practices in the population assessment of problem gambling. Guelph, Ontario: Report submitted to the Ontario Problem Gambling Research Centre; 2010

64. Braverman J, Tom MA, Shaffer HJ. Accuracy of self-reported versus actual online gambling wins and losses. Psychol Assess. 2014;26(3):865-77.

65. Auer M, Griffiths M. Self-reported losses versus actual losses in online gambling: an empirical study. J Gambl Stud. 2017;33:795-806.

66. Canale N, Vieno A, Griffiths M. The extent and distribution of gamblingrelated harms and the prevention paradox in a British population survey. $J$ Behav Addict. 2016;5:204-12. https://doi.org/10.1556/2006.5.2016.023.

67. Browne M, Greer N, Rawat V, Rockloff M. A population-level metric for gambling related harm. Int Gambl Stud. 2017. doi.org/10.1080.14459795. 2017.1304973.

\section{Ready to submit your research? Choose BMC and benefit from:}

- fast, convenient online submission

- thorough peer review by experienced researchers in your field

- rapid publication on acceptance

- support for research data, including large and complex data types

- gold Open Access which fosters wider collaboration and increased citations

- maximum visibility for your research: over $100 \mathrm{M}$ website views per year

At BMC, research is always in progress.

Learn more biomedcentral.com/submissions 